\title{
PABLO BOCZKOWSKI: FOR THE REVISION OF THEORIES AND A NEW FOCUS ON AUDIENCES
}

\author{
PABLO BOCZKOWSKI: PELA REVISÃO \\ DE TEORIAS E UM NOVO FOCO NO PÚBLICO
}

\section{Marcelo Crispim da Fontoura}

Doutor em Comunicação Social pela Pontifícia Universidade Católica do Rio Grande do Sul (Porto Alegre/Brasil). Professor adjunto de jornalismo e comunicação digital na Pontifícia Universidade Católica do Rio Grande do Sul (Porto Alegre/Brasil).

Professor substituto de Estudos Básicos da Comunicação na Universidade Federal do Rio Grande do Sul (Porto Alegre/Brasil)

E-mail: marcelo.fontoura@pucrs.br 


\section{Brazilian Creative Industries}

\section{ABSTRACT}

Pablo Boczkowski, professor at Northwestern University, has an influential career in Journalism Studies. In his first book, Digitizing the News, Boczkowski has described the early efforts of newsrooms to deal with digital media. His latest book, Abundance, is based on 158 interviews with media consumers in Argentina and analyzes how they establish routines and strategies over media. In this interview, Boczkowski discusses his legacy, the challenges that a new information environment poses to classic theories, and his focus on the research of audiences.

Keywords: Pablo Boczkowski. Journalism Studies. Digital media.

\section{RESUMO}

Pablo Boczkowski, professor da Northwestern University, tem uma carreira influente em estudos de jornalismo. Em seu primeiro livro, Digitizing the News, Boczkowski descreveu os primeiros esforços das redações para lidar com a mídia digital. Seu último livro, Abundância, é baseado em 158 entrevistas com consumidores de mídia na Argentina e analisa como eles estabelecem rotinas e estratégias sobre a mídia. Nesta entrevista, Boczkowski discute seu legado, os desafios que um novo ambiente informacional impõe às teorias clássicas e seu foco na pesquisa de audiências.

Palavras-chave: Pablo Boczkowski. Estudos de jornalismo. Mídia digital. 


\section{Brazilian

\section{PRESENTATION}

It is not frequent for an academic work to mark the development of a whole field. Pablo Boczkowski, the Hamad Bin Khalifa Al-Thani Professor at the School of Communication of Northwestern University and author of works such as the influential Digitizing the News, News at Work, the News Gap and the more recent Abundance, can claim this achievement. Digitizing the News, his first book, published in 2004, has been prominent in demonstrating the materiality in the relations that journalists established with digital technology in the 90s. It has also brought ethnography as a method back to light in Journalism Studies, influencing other such endeavors in the field. Boczkowski, however, argues that the main legacy Digitizing may have left is the attempt to go against technological determinism when analyzing how people interact with technology (at the time, he was concerned with how newsrooms were doing their first digital experimentations). This very same lesson is at the core of his new book, Abundance - On the Experience of Living in a World of Information Plenty (Oxford University Press, 2021).

While previous works have focused on news production or products, in his latest book, Boczkowski has turned his attention completely to audiences and their routines. The aforementioned subtitle of the book sums up its overall goal: how do people interact with media in a world where it is abundant, and where so many different stimulus and options compete for attention? What rituals and meanings are involved? This is also Boczkowski's first book about manifestations other than news, like social media, TV and entertainment in general. He recommends the experience of changing topics: "it gives you a very different appreciation of news reception when you also hear people talk about what Game of Thrones means to them. I highly recommend, for those who are interested in one genre, if they can, to study the other as well".

One aspect that has not changed, though, is Boczkowski's concern with the exaggeration of technology's role in our media life. He fiercely argues against what he calls "moral media panics", which can be seen in documentaries such as The Social Dilemma, and in views that consider current media habits as completely discontinuous from previous practices. Abundance, on the contrary, turns its glaze to regular people in Argentina and how they make sense of media, describing the diverse, complex strategies and meanings involved in consumption of media. These insights, he adds, call for a revision of classical communication theories.

In the following conversation, lightly edited for clarity, Boczkowski discusses these topics, revisits his legacy as researcher and indicates new endeavors. 


\section{Brazilian \\ Creative Industries}

Interviewer: To begin our discussion, I would like to talk about your first book, Digitizing the News, a very relevant work. Of course, it became a huge reference in the realm of digital journalism. So, I would like to start asking you what do you consider to be the legacy that Digitizing the News leaves to the academic journalistic field?

Pablo: That's a great question. And thank you again for the interview. Digitizing the News was conceived as a project, really, almost a quarter century ago. I began doing research on online news exactly 25 years ago, in 1996. And I decided to do the study that led to Digitizing the News in 1997. Back then there was really no research on technology in the newsroom. The ethnographic study of news production had been quite dormant for many years, and the classics in the field like Ganz, Tuchman, etc., hadn't really wrestled with the materiality of news work. So, what I set to do in Digitizing the News was to bring an STS ${ }^{1}$ perspective into the study of news production, to bring communication and media as a relevant subject within STS. It was a two-way street because the sociology and the history of technology were mostly concerned with other kinds of technologies like, nuclear missiles, cars, bridges, big things. In the state of media artifacts, there were a few references that we know were important, but it wasn't formed as a domain of inquiry within STS. So, when I did the ethnography, because Digitizing the News combines archival research, the historical dimension, and the ethnographic part, it was evident to me that I needed to bring also a work and organizational dimension to it. Because a lot of what was relevant had to do with organization of work, some of which had been covered by the classics, but not really theorized within that literature. In Digitizing the News, we see the intersection of these three sorts of literatures and three domains of inquiry, sociology of work had not really paid attention much to media work. At that point, tangentially to technology, it ended up, as you say, becoming a very influential book who was sort of the first of many ethnographies of news production that ended up paying attention to technology and it ended up paying attention to work. You know, 17 years after its publication, almost 18 in February of next year, I think... So, from the vantage point of today, given where the discourse is today, the legacy probably is an antidote against the technologically deterministic dystopic narratives that have taken hold of the study of digital news and news in general in society. Digitizing the News was written at a time in which most of social sciences were beginning to debunk technological determinism. And nowadays, no scholar would say that they are deterministic, but a lot of the scholarship today is implicitly deterministic. So probably the main legacy is that: to remind ourselves that processes of social technical construction

\footnotetext{
1 Science and Technology Studies.
} 


\section{Brazilian \\ Creative Industries}

are contingent, that structures do have power, but the power is not unlimited, and that actors have power as well. Also local conditions and contextual factors of different kinds really interact with the power of structures. The result, therefore, is never determined by technology or by social structures, but emerges at the combination of both. We live at a time in which the return of moral media panics has been quite striking. I mean, the popularity of The Social Dilemma or a lot of the media commentary, many of which is done by scholars, that has an incredibly dystopian and deterministic tone, and a significant amount of scholarly work, that, again, it doesn't say that it is deterministic, but the claims are, are quite striking. So, from the vantage point of Digitizing the News, at the time it was written, it is as if we haven't learned much. Hence the legacy is a reminder that we know a lot of things, and that these technologies, unless they are incredibly different from all other technologies in history, and there is no reason to believe that that is the case, even also the empirical results that we have from a number of studies, [are not dominant]. We need to pay attention to agency, to work, to contingency and to local contextual factors.

Interviewer: As you said, it's been 17 years. They say hindsight is always 20/20. Is there anything you think maybe you missed or maybe you got wrong in the Digitizing the News?

Pablo: Oh, I'm sure that I missed many things. In terms of getting wrong... Relative to what I wanted to explain, I think the account is fairly robust. It's interesting, the other day I had to put together for somebody the reviews of the book, the book was well reviewed everywhere. I mean, not just in communication, but in business history, history of technology, in management, in sociology, etc. I mean, there were quibbles here and there. Probably it's not so much about getting wrong. What Digitizing the News didn't do, because he didn't set out to do that, was to talk about publics and audiences, which is typical in the sociology of news production. It stops. That was a void for me. I didn't realize it was a void until I think it was in 2005, if I remember correctly. Shortly after its publication, Ev. Dennis, who was then the Chair of the department at Fordham University, he is now retired or in the process of, but 17, 16 years ago, he invited me to give a talk at Fordham. It was a very unique moment because I met Leo Bogart then, the famous researcher, who I had long admired, and, in the audience, there was a very young Phil Napoli, when Phil was there, and Phil asked me the question of, well, what's the impact of everything that I am studying, something along those lines. I provided some answer, but then I realized that I, as an ethnographer, I could not talk about impacts because I don't have any data on the public. That question and that void was what launched what is now a 15-year research program into the behavior of the public. News at Work was the transition book, because it combined the production of news and the consumption of news. And after News at Work, it was 50/50 in the split. Then, for The News Gap, it was like $90 \%$ of the public and there was about $10 \%$ in terms of the 


\section{Brazilian \\ Creative Industries}

ethnographic side. Well, I should rephrase that because we didn't do research on audiences, but I mean, News Gap could also probably be considered 50/50. We did interviews with editors and reporters within the interviews with the audience. But then, what followed that, Abundance is entirely on the audience and the digital environment is also a significant amount on that. So, I would say that the main thing that Digitizing the News doesn't have, because it didn't set out to do, but it would have an interest in doing it, got to do with the reception of the news that was being digitized. Evidently, I was just writing a dissertation and then a book. I was completely mindless about... it's not that I said, 'okay, I have this grand idea and I'm going to revolutionize the field' or anything like that. But it has played an important role. And I don't know if you know this, but the book came out the same year that the Journalism Studies division was founded at ICA, and it's credited in part with sort of relaunching the study of Journalism at ICA, and institutionalizing it to the point of, when the Journalism Studies division celebrated its 10th anniversary, it was also the 10th anniversary of the book. So, Seth Lewis did a special session at ICA, it was a retrospective on the book in the context of the institutionalization of Journalism Studies. Steen Steensen spoke, Chris Anderson spoke, Nikki Usher... I can't remember who else. I said a few words. But, yes, I realize it's been influential. I'm still in touch with many of my key informants, believe it or not.

Interviewer: So, let's transition a little bit to Abundance. Of course, there is quantitative research which you combine to the qualitative aspect. But it seems to me that it's mainly qualitative. There is a strong qualitative aspect to your research. What do you think is the role of qualitative research in a world of increasing quantitative expectations?

Pablo: Abundance is a very romantic book, romantic, not in the sort of romantic relations, I mean in a classic sense, in the sense that it tries to go a little bit against the grain. As you said, we live in a world in which big data and computational social science seem to have the promise to solve everything. And the problem with that promise is that it is based on the premise that meaning can be reduced to numbers. For computation to take place, everything has to be reduced to zeros and ones. And the domain of meaning is not reducible to that. The domain of meaning can only be understood if you adopt the subjects' perspective, and if you deploy methodologies to try to get at what things mean to the people who are doing them. And that requires qualitative methods of various kinds. If you were doing historical work, it would be more of archival research, if the subjects are alive, it is interviews, observation, etc. Because of the nature of what I'm interested in, which is, personal private behavior, I don't feel comfortable going into somebody's house and hanging out there for a long period of time without having developed trust. I did some of that for Digitizing the News, for instance, in the case of one reporter who worked in the home. But I had already 


\section{Brazilian \\ Creative Industries}

built a relationship, so I can hang out with that person, grab a chair and shadow him in his home. But I have 158 subjects, interviewees, in Abundance. And I didn't do the interviews, I had a team doing interviews. I mean, big data can be important, but small data can be beautiful. It's the beauty that emerges from meaning, from the polysemy of meaning. I do not believe that everything can be reduced to numbers. The problem with a lot of the computational social scientific work, which is, in many ways, helpful, is that, in many times, it doesn't really specify the scope conditions of what it cannot do. Not only what he can do, but what he cannot do. And by implication, therefore, it is assumed that it can do more than what it actually can. So that's why there is a survey research component to Abundance that was taken so that I would get a big macro picture, but the core of the book is based on the interviews. That was on purpose, for this very reason that I wanted to understand how meaning, emotion and practice really shape, or to what extent they shape the reception experience. I didn't think, and I still don't think, that if you gave me a million terabytes of data that I will be able to get at that. I'd rather have a hundred interviews than a million terabytes.

Interviewer: There is a strong defense in Abundance of Argentina as the locus of research. Also, by the end, you mention this idea that the studies from the Global South might be universal and studies from the Global North might be specific. All that said, do you think the results of Abundance can be extrapolated at least to other Latin American contexts?

Pablo: Very good question. I wouldn't claim that studies from the Global South are universal and studies from the Global North are not. What I would say is that there is an interesting inversion in the world of the academy and other worlds, or social arenas, that has to do with power, whereby the minority pretends to be the majority. But it's really only a small minority. It's not even $43 \%$, let's just say. It is really $13 \%-14 \%$ of the world live in a very small number of countries of all the countries that exist in the world, and where a disproportionate amount of the research takes place. Which is fine that there is a lot of research on these countries. I mean, I think it's wonderful that there is research on any country. But again, they should contextualize their findings in the same way that we are asked to contextualize ours. So, what I would say is not that the research from the Global South is universal, but they represent the majority. We should not forget that. It is a clear evidence of power imbalance, that those of us who study the majority have to justify why we do that, while those of them who study the minority do not have to do that. It should be actually, if you think about it, the other way around. There is also a problem with the notion of the Global South, in the sense that it does help to differentiate middle- and low-income countries, essentially, from high-income countries, but it obscures a lot of differences among countries. Hence your 


\section{Brazilian \\ Creative Industries}

question is about generalization and generalizability of the findings. In many ways, perhaps some of the findings from Argentina resonate deeply with patterns in India, based on what I've seen in the research. And it's interesting, because they are an ocean apart, two, actually, and with many striking differences in history. But the issues are having to do with a strong associational culture, a gregarious character of everyday life in these societies, the role of familiar patterns, the role of institutions in the polity that have Iong disfavored vast segments of population etc., and then there are many other differences. So, I do not dare to say that any of the results of Abundance can be generalized, but that perhaps can evoke and resonate with other settings. In the case of Brazil, it has been very interesting to me. So, Brazil is a country that, growing up in Argentina, I have long admired the culture of Brazil, the natural beauty of the country, etc. It's a country that has always sort of fascinated me. And I was mentioning to you that I've been giving a lot of talks about Abundance. Brazil is probably the country with the highest number of talks. This afternoon, I have a conversation scheduled with a colleague of yours from another university to schedule a talk there as well. So, evidently, there is something that resonates, from both the argument and what you call a strong defense of Argentina. I think in part what resonates is... So, one of the things that sets Brazil, in my modest understanding of its 20th century history, and correct me if I'm wrong, but my very limited understanding is that Brazilians have a significant pride of place. So, in the Anglo-Saxon academy, there have not been very many books done withing the Global South that argue that they are not a lesser version of the Global North of a situation, but that argue that there is something unique about the setting that makes the study particularly good there. Because the justification that I offer is the justification from a position of strength rather than a position of weakness. 'Oh, I'm sorry, I didn't do this in the US or the UK or Norway or Germany, but still we know less.' The typical justification is 'we know less about the Global South, we know less because of the power inequalities in the academy'. But that's not enough justification. There are things that are unique to Argentina that makes it particularly interesting to what's going on in the Global North. My sense, from my conversations with Brazilian colleagues is that that part really resonates. That resonates within a national culture that has this strong pride of place and feels somewhat sort of removed to the sidelines of the international conversation. But there are also significant differences between Brazil and Argentina. Brazil is a very large country. Within Latin America there are other countries that do not have Spanish as their main language, but it's by far the largest one. In part, because of that, it has evolved sort of in a culturally distinct environment than other Latin American countries in their relationships with themselves. It has been absolutely wonderful the reception among Brazilian colleagues. I've given talks on sort of the evolving findings from this project for about three years until it was published and now, thousands of talks. I have given talks in many countries, in many continents, and there is much similarity. The findings evoke. I remember a colleague at MIT, when I gave a talk there are a couple of years 


\section{Brazilian \\ Creative Industries}

ago, he said, 'well, if you didn't tell me it was Argentina, I could think that this is happening in Boston'. Which is another thing that is interesting. I do a lot of comparative research. In this project, the data comes from Argentina, but in parallel we did a comparative study with colleagues in Finland, Japan, and Israel, in addition to myself in the US as well as in Argentina, and a colleague in Argentina, and we've published a number of papers. What has been striking to us is that there is significant repetition of patterns across sites. The manifestations are different. I mean, you would think that Finland and Argentina, there is very little that they share culturally, right? Nonetheless there are interesting patterns of resonance. So, the other thing that I think that, from an Anglo-Saxon perspective, it's not only that we know very little about most of the countries in the world, is that when we tried to know, we tried to know from the position of the other: 'oh, that's exotic, that's the other, that has to be different'. I make a lot of gestures in Abundance, particularly towards the US to say, 'well, things are not very different in many regards.' A lot of the pressgovernment relationships during the Trump administration had striking resonance with the pressgovernment relationships when Hugo Chavez was president of Venezuela. The dynamics in the US as followers, not as first movers. Not as initiator. I think it is important when one does research outside of the center, only in a comparative fashion, not to start with the premise of difference, necessarily. Also not start with the premise of sameness, but I mean, not start with any premise. Because we are seeing differences, but also significant continuities, and the same historically. That's the other thing that I tried to do in Abundance. It is not like in Digitizing the News. I did not do historical research, not even recent history research, but I did read profusely the historical literature. I actually talked to probably the main historian who has studied issues of information abundance in the early modern period and the Renaissance, to try to figure it out what are the areas of continuity. Not just the discontinuity. Because the other thing that we do in the literature a lot is we emphasize discontinuity, what's new. That is what sells, but there is much more that is continuous. A lot of the stuff that we talk about. For instance, if you think about the research on social media. One of the main new concepts that had been sort of developed is this idea of the context collapse. The context collapse is something that was very discussed by Joshua Meyrowitz in his study of television, No Sense of Place. My colleagues who work on context collapse in social media do credit Meyrowitz, but there is almost no effort to explore, well, what is it that is really new about social media. We start again with the assumption of difference, that what we are studying now is really, really, really very different. Is it? Ambiance journalism, I mean, it characterized people's relation to radio news since the 1920 s in some ways. I'm for sure it characterizes how people consume TV, I talk about that in the book at length. The consumption of television is ambient for the most part. In that sense, our engagement with this prior media prepares the ground culturally for the new media. It's not that there is nothing new about the new media, in the same way that it's not that there is no difference between Venezuela and the US. 


\section{Brazilian \\ Creative Industries}

There are differences, but there are lots of continuities and similarities. The task of research is to figure out, first of all, what is continuous and what is discontinuous, and secondly, why. Is it really the technology? Is it culturally? Is it a combination of both? For instance, why does WhatsApp have the place that it has outside of say, for instance, the US as the main platform? Part of it has to do with issues of political economy, pricing decisions of messaging. Part of it has to do with associational cultures. And why is it that in, certain countries, voice messages of WhatsApp are very prevalent and in others, not. Again, it has to do with the role of conversation in daily life and how much people are used to. But those are the questions that I think are worth asking. That's where a comparative, cross-national sensibility is useful, even if you don't do the comparative work, but understanding that no places is either the other or the center. Even if you don't do the primary research in other countries, you have to read the literature and to second that literature and use that as background to assess what your findings mean.

Interviewer: I love the expression you use about this very subject, the 'contemporary bias'. It's very common to see this contemporary bias. I think it's Ta-Nehisi Coates who uses the expression 'the bias of now' referring to journalists

Pablo: We have that bias, in particular those of us who study digital media. And that's why I think part of the legacy of Digitizing the News, perhaps, is also the combination of recent history with the ethnography. Most of the people, my colleagues, students who talk about Digitizing the News, they talk about mostly ethnography, but I think it is very important in particular in this age of recurrency of moral panics about the media.

Interviewer: Let's talk about routines, which is a very important aspect of Abundance. You describe the role, the centrality of routines in news consumption, but other types of consumption as well. Did you observe any difference in routines and habits towards news regarding political preferences?

Pablo: No. The content of the routine is different, but not the character of the routine per se. No, I did not observe that. In general, not just for news but for entertainment. I'm trying to think... I think that's another Global North, in particular US, bias, in the sense that over the past five years, we have had ample research, and, in my opinion, the best that I've read is Yochai Benkler's work on network propaganda on this, where he talks about this idea of asymmetric polarization. The idea of polarization is that you have two sides, maybe more than two, but it's usually two, and they have very different takes on the same issue. The idea of asymmetric polarization is that there is something about one part of the equation, one 


\section{Brazilian \\ Creative Industries}

side, that is not commensurate with the center or with the other side. It's a different kind of rationality, it's a different kind of belief system. It is essentially a denial of the elemental basics of reality. That phenomenon appears to be, at that scale, prevalent in the US, for sure. It's very well documented by Benkler and his analysis is superb, I think. But I have not seen that in Argentina, which is a country with a longstanding history of polarization. But I think what usually surely happens as a derivation in public discourse in the academy and in the media contending with the relations of asymmetric polarization is the idea that there is one side that is wrong, that is particularly wrong, that is bad, bad, bad, bad. That might be the case in the US, but that doesn't necessarily mean that every time you have polarization, you have one side that is bad, and it's usually the right wing, and the others are not. I don't know in other countries, like in Brazil, with supporters of Bolsonaro, or in Hungary, with supporters of Orbán, or in Turkey with supporters of Erdogan, I do not know, I do not claim to know. But, in the case of Argentina, I do not think that the right-wing voters, or the majority of the right-wing voters, have a different sense of the basic elements of reality than the left-wing voters. And where this plays out, for instance, contemporaneously, is that if you've been following the American press, you see that COVID vaccine hesitancy is particular prominent in districts that voted $60 \%$ or more for Trump. It correlates. But there is nothing ideological about the manufacturers of the vaccine, it's just a reality denial mechanism. It is living in this parallel, alternative universe, but you don't see the same in Argentina. Argentina has a very high level of vaccine acceptance. Vaccination rates are higher than in the US now. That's why the routines might be different in the States, I don't know, but in Argentina I did not see them. And I think it's important to distinguish the character of routines, how practice is organized, with the substance of the practice per se. The thing is that, very anthropologically, if your belief system is radically different from the belief system of $80 \%$ of society, perhaps your routines become different. But I wouldn't say that that applies to the Argentine case massively. The main point that I'm trying to impress in the book is that media routines are part of broader routines of everyday life in which the focus is primarily not media. And that's something that I learned from this project that I hadn't realized before. It's the fact that most of us who study the media, but particularly more for those of us who study the news side of the media rather than the popular culture and entertainment side. For us, we think that the media are very important in society, and the people who we study, the journalists, also tend to think that the media are very important in society. They realize, the journalists, that regular citizens do not think that the media are so important, but they think they are still very important. We academics have tended to think the same. My sense is that, I don't know before, but nowadays most of the media routines are derivative, in particular news media routines, perhaps not so much entertainment routines. So, media routines should be seen as a subset of broader routines of everyday life. Therefore, if that is the case, what explains media behavior is not really media related. It's about the routines of everyday life. What do I mean 


\section{Brazilian \\ Creative Industries}

by this? If we consume the news incidentally primarily, so, the main way in which we inform ourselves about current events is in an incidental fashion, we do need to understand the broader routines within which there is sometime an opening to get the news. For instance, if we get most of our news in the empty times in which we are not doing something, so, 'oh, I had to go to the supermarket, and there is a Iong line waiting to pay, so, for three minutes I read news. And I stop or not, depending on when I'm there'. So, if I'm reading news, there are certain things that I'm not going to read, number one. Or certain videos that I am not going to watch. Number two, the time is the time of the queue to pay for groceries. It's not really the time that I want to devote. It doesn't say anything about how much [time I want to devote]. But we don't study those things. We study as if news consumption was the primary focus of attention and abstracted from anything else. And that's not really the case. It's not the case in part for entertainment either. And that, if my intuition is right, requires a tremendous amount of rethinking of our main theories. The theories that we have are remarkably consistent, I mean, I have a colleague here at Northwestern who was the first author of a study where he and his coauthors did a content analysis of every paper that was published in journals of communications since their founding until 2016. Every single paper, and they caught it on a number of dimensions. One of them was the theories used. And what they show is that there is very little theoretical innovation in the field. It's always the same handful of theories, but those theories were developed when the media system was radically different, and when people's relationships with the media were radically different. I think we really need to revisit that. Agenda setting, for instance. For agenda setting to function we need media that really intermediates, number one. Number two, people who pay attention. We know that people don't pay attention. And we also know now the media intermediates less and less. My favorite example of this is, and I'm sorry to bring up a subject that, maybe not for you, but maybe for some of your readers, might be difficult, when Argentina defeated Brazil in the Maracanã Stadium for Copa América. It was the news of the year for Argentines. The only happy news probably of all of 2021. So, it was all over television, as you might imagine. Every program became a sports program. I wasn't there, but I was told that it was very common that what news organizations would do was that they would just plug the live Instagram coverage of the players in the locker room, and they would show that in the big screen. There is no difference. There is no intermediation, there is no different in going through your Instagram account and seeing that, or seeing that on cable news $X, Y$, or $Z$. If you go to Instagram, I looked at one of those, it had like a 50 or 60 minute coverage of that, and the player had 10 million views on Instagram. The production values were horrendous, the phone dropped on the floor. It was Instagram, and for an hour, almost. And 10 million people watched that. Ok, they had 10 million views, maybe not 10 million people, maybe someone watched a hundred times, but it tells you a lot about who actually intermediates and whether there is an intermediate. I mean, that says there is no 


\section{Brazilian \\ Creative Industries}

intermediation, you have a source becoming the reporter, which is anathema to the principles of modern journalism. What I'm telling you is not an exception. It happens all the time now. For many types of news. I think if we follow the subjects through their routines, we see routines that tell a very different story from the theoretical story that we teach. And the disjuncture is massive. I think it affords a tremendous opportunity for us to rethink the very basics of how we understand communicating. Another example from the world of soccer that I've been using lately, when Messi scores his first goal with Paris SaintGerman, first goal in his club career that is not with Barcelona, it was at a fairly inconsequential match, and it was a fairly inconsequential goal. I mean, Paris Saint-German was winning 1x0 and ended up winning 2xO because of this goal, but it was symbolically an important goal. So, Messi posted five pictures of that on Instagram, after which they had almost 14 million likes. Not views, likes, so somebody not only was exposed to that content, but spent a fraction of a second liking. The New York Times needed between 200 and 250 posts on Instagram to altogether collect 40 million likes. The NYT is the most powerful media organization of English speaking language versus the best striker in the world, the best player in the world. But it's one person versus the organization. The power of the media, who sets the agenda, what interests the audience, all of these things are at play in that very simple example. But that's not necessarily what we teach or what we theorize.

Interviewer: In the same subject, the Communications literature is historically focused on manipulation and passive audiences. And this idea is still too prevalent. Why do you think that is?

Pablo: Because it's easy. The literature theoretically has demonstrated active audiences and has demonstrated that it's impossible to manipulate, or not impossible, but the possibility to steer behavior is limited. Yet, there is this focus on the idea that the medium, the new media, can manipulate, and that audience is by and large manipulable. This is what I was alluding to before as this moral media panic, that already existed when films were first shown. 'Oh, they're going to corrupt the mind and the soul', etc. It happened with television, and we know it's not true. I think one reason why the discourse has again become so prevalent among media professionals, as well as among academics, is that it provides an explanation that situates the main causal forces outside of the domain of certain actors and places it entirely in the domain of others. One thing is that it makes us not responsible, because, since we are passive and we can be subject to manipulation, there is nothing that we need to do. It is the big corporation, the technology affordances, the algorithm, etc. So, it's easy. It's an easy answer. It's an answer that says that there is nothing that we have to do. The flip side of that is that, because it does all of that, it turns us from historical subjects into historical objects. And the problem with that is that it disempowers us. Social 


\section{Brazilian \\ Creative Industries}

science is performative. That is, the theories that we have explanations, that we give in the world do have effects in the world. You can't really change the behavior of a virus if you give wrong explanations. But you can change the behavior of society. It's been demonstrated by Donald McKenzie, in his study of economics and financial markets. These explanations, I believe, have become so prevalent because they exonerate, they do not require us to think about some structural issues in society that we might know what to think about. But, on top of the fact that they are wrong, they do a fundamental disservice by disempowering us and turning us into historical objects. And they have been particularly prevalent in the past five years. 'How come we got Brexit?', 'how come we got Trump?', 'how come we got Bolsonaro.' It's easier to say 'it's the media', 'is the algorithm', 'it's a handful of companies' versus 'there are all these issues in society that are long-standing that are difficult to solve, but if we don't tackle them, they will not go away'.

Interviewer: Let me just ask a final question. You just tackled abundance. You have researched digital newspapers in the past. You mentioned an increasing interest in the audiences. What would you say is your next research interest, or your next research step in the field?

Pablo: It's a good question. I've been doing research for 25 years now, give or take, I started with news production in the Global North - Digitizing the News is in the States - and then I've been branching out in terms of area of study, in terms of methodology and in terms of geographic focus. Digitizing the News was a study of news production in newspapers in the States. Then what followed is that I went from that to Argentina with News at Work, and I went from only news production to news production, news products and news consumption. Then, in The News Gap, I went from either the US or Argentina to a comparison of seven countries, both news production/news consumption. In Abundance, what I did is I broadened from news to many other media practices: entertainment, social media, etc., on the consumption side. And as part of, as I mentioned before, a larger comparative project in five other countries. I have a number of projects at work. One is a theoretical project, a book that is on the contract with MIT Press. Exactly a week ago we sent the full manuscript to the press for another round of review. The book is tentatively titled Social Media Studies - Comparative Perspectives, and is a theoretical book on the need for comparative work in the study of social media. It's not about news. This will be my first book with no news component. I'm doing that with a colleague. And then in parallel I have, with three other colleagues, a book proposal in the review with a couple of publishers that looks at the reception of misinformation, not the production of misinformation or the distribution of misinformation, but the reception of misinformation in the context of the 2019 presidential election in Argentina. If it actually gets published and I hope it will, I hope somebody will like it, it will be my first book using experiments. So, in that work we combine six months of interviews, 


\section{Brazilian

we interviewed people every week for a period of six months, and, during that period, we did three waves of panel survey experiment. So, we did the surveys, and we did the experiments, informed in part by online experiments, by the field research. So, it was a combination of interview surveys with experiments, to really test mechanisms at the micro level. So, I have these two and then I have a couple of other projects in my mind, not really in the area of news. As my career has continued, I have sort of been branching out of topics, adding different topics. I have to say Abundance is my first book where I studied entertainment. It has given me an entirely new appreciation of news. I think the division of labor in the field between the study of news and the study of popular culture is very unfortunate, because we do not say 'oh, now I want to read news, or now I am going to watch this show'. Everything is in part intertwined and more and more is woven together, and you see this in particular in terms of the rise of historical fiction and all of that, that the boundaries between the two are quite tenuous. And it gives you a very different appreciation of news reception when you also hear people talk about what Game of Thrones means to them, or about how that experience is to them. I highly recommend, for those who are interested in one topic, one genre, if they can, to study the other as well. 